\title{
Some Volatile Aroma Components of Vitis Vinifera L. cv. Sauvignon blanc*
}

\author{
O. P. H. AUGUSTYN, A. RAPP AND C. J. VAN WYK
}

Respectively from the Oenological and Viticultural Research Institute (OVRI), Private Bag X5026, Stellenbosch, 7600, Republic of South Africa; the Bundesforschungsanstalt (BFA) für Rebenzüchtung Geilweilerhof, 6741 Siebeldingen (über Landau/Pfalz), Federal Republic of Germany; the Department of Oenology, University of Stellenbosch, Stellenbosch, 7600, Republic of South Africa.

The authors wish to express their thanks to the following persons: Mr. H. Ullemeyer (BFA) for recording of mass spectra and discussions on interpretation of data, Mr. W. Knipser (BFA) for his aid with the interpretation of several spectra, Dr. C. Campbell, Rupert International, for recording of mass spectra, Dr. W. Pickenhagen, Firmenich, Geneva, Switzerland for the supply of certain reference compounds and Mr. S. Back, Backsberg Estate, Paarl, for supplying part of the required Sauvignon blanc grapes.

Submitted for publication. September 1982

Accepted for publication: October 1982

\begin{abstract}
Volatile aroma components of Vitis vinifera L. cv. Sauvignon blanc grapes were studied to identify the components responsible for the characteristic aroma of this grape cultivar. Thirty three volatile components were identified. Amongst these methional and trans-2, cis-6-nonadienal are reported present in Vitis for the first time. Evidence is also presented for the presence of three methoxypyrazines which are believed to be key substances responsible for the typical aroma present in grapes and wines of this cultivar.
\end{abstract}

Vitis vinifera L. cv. Sauvignon blanc, one of the traditional cultivars of the Sauternes and Sancerre regions in France, is also planted extensively in other wine producing regions of the world. Wines made from this cultivar have a distinctive aroma and are easily distinguished from wines of other white cultivars (Chaudhary, Kepner \& Webb, 1964).

The typical aroma of local Sauvignon blanc wines has been described as asparagus-like, green, grassy, green pepper-like, pyrazine-like, often with a fruity/floral note, especially in young wines. The characteristic smoky aroma, sometimes associated with wines of this cultivar (Amerine, 1982), especially in wines from the Sancerre, is rarely encountered here.

In South Africa, grapes of both Sauvignon blanc and $V$. vinifera cv. Cabernet Sauvignon are frequently characterised by a pyrazine-like flavour which may, however, vary in intensity. Bayonove, Cordonnier \& Dubois (1975) identified 2-isobutyl-3-methoxypyrazine in grapes of the latter cultivar. This compound has an extremely low odour threshold (Buttery et al., 1969), and Bayonove et al. (1975) speculated that it could play an essential role in the dominant green note which characterises grapes and wine of Cabernet Sauvignon.

No aroma impact components have yet been identified in Sauvignon blanc grapes or wines. This study was, therefore, initiated in order to identify the components responsible for the typical cultivar aroma in Sauvignon blanc, and is part of an investigation of the cultivar aroma in Cabernet Sauvignon and other aroma related $V$. vinifera cultivars e.g. Ruby Cabernet, Cabernet franc, Merlot and Malbec.

\section{MATERIALS AND METHODS}

Origin of samples: Grapes were harvested during 1981 and 1982 at Backsberg Estate, Paarl and the OVRI and Welgevallen experimental farms, Stellenbosch. Samples were taken from seven year old vines grafted on 101-14 and bearing thirteen tons per hectare. The area has a Mediterranean climate with a heat summation over the growing season of 1946 degree-days. This places the locality in region IV according to the classification of Winkler et al. (1974). The grapes from Paarl were harvested at between $15^{\circ}$ and $18^{\circ} \mathrm{B}$, while those from Stellenbosch were harvested at $22^{\circ} \mathrm{B}$.

Preparation of extracts: (a) Freon 11 extracts were prepared under conditions of partial enzyme inhibition as described by Augustyn and Rapp (1982). Extractors of $3 \ell$ capacity were used in place of the $250 \mathrm{~m} \ell$ units used by the latter authors, and no internal standard was added. Material was extracted over 48 hours with the $50 \mathrm{~m} \ell$ freon 11 in the extracting flask replaced after 24 hours.

(b) Headspace extracts were prepared from grapes from Stellenbosch by the technique of Rapp \& Knipser (1980).

(c) Portions $(300 \mathrm{~m} \ell)$ of the freon 11 extracts were separated into neutral and basic fractions by shaking the freon extract with $10 \% \mathrm{HC} 1(3 \times 300 \mathrm{ml})$. The $\mathrm{HCl}$ fraction was neutralized with $20 \% \mathrm{NaOH}$ and the volatiles extracted with freon 11 . Moisture was removed from the extracts by freezing $\left(-77^{\circ} \mathrm{C}\right)$.

All extracts were stored in glass containers at $-15^{\circ} \mathrm{C}$. Samples analysed in Germany were transported in glass ampules. Extracts were concentrated under partial reflux in small drawn pear-shaped flasks on a waterbath at $28^{\circ} \mathrm{C}$ as described by Augustyn \& Rapp (1982).

Gas chromatography: (GC) Parameters and columns used:

$\mathrm{C}_{1}$ : Reoplex 400 (150 m, 0,46 mm I.D.); Temperature programme: $50^{\circ}-150^{\circ} \mathrm{C}$ at $1^{\circ} \mathrm{C} / \mathrm{min}$., Carrier gas: $\mathrm{He}$; head pressure $260 \mathrm{kPa}$; no split; detector mass spectrometer (MS).

$\mathrm{C}_{2}$ : Reoplex 400 (150 m, 0,46 mm I.D.); Temperature programme: $50-150^{\circ} \mathrm{C}$ at $2^{\circ} \mathrm{C} / \mathrm{min}$., Carrier gas: $\mathrm{H}_{2} ; 100$ $\mathrm{kPa}$; no inlet split; exhaust split $1: 9$, detector FID.

$\mathrm{C}_{3}$ : Reoplex 400 (65 m, 0,25 mm I.D.); Temperature programme $50^{\circ}-150^{\circ} \mathrm{C}$ at $1^{\circ} \mathrm{C} / \mathrm{min}$., Carrier gas: $\mathrm{He}$; at $1 \mathrm{~m} \ell / \mathrm{min}$., inlet split $30: 1$; exhaust split $1: 1$; detectors FID and TSD (N/P detector).

$\mathrm{C}_{4}$ : Reoplex 400 (65 m, 0,25 mm I.D.); Temperature programme: $50^{\circ}-150^{\circ} \mathrm{C}$ at $1,5^{\circ} \mathrm{C} / \mathrm{min}$., Carrier gas: $\mathrm{H}_{2}$; at $1.4 \mathrm{~m} \ell / \mathrm{min}$., inlet split $30: 1$; detector FID. 
$\mathrm{C}_{5}$ : Carbowax $20 \mathrm{M}$ (23 m, 0,25 mm I.D.); Temperature programme: $50^{\circ}-180^{\circ} \mathrm{C}$ at $1,2^{\circ} \mathrm{C} / \mathrm{min}$., Carrier gas: He; with flow adjusted to give a methane dead time of $35 \mathrm{~s}$, no split; detector MS.

$\mathrm{C}_{6}$ : Reoplex 400 (3 m x 3 m I.D.); packing, $5 \%$ on Chromosorb G HP, 80 - 100 mesh; Carrier gas: $\mathrm{N}_{2}$; $30 \mathrm{~m} \ell / \mathrm{min}$., exhaust split 1:9; detector FID.

Temperature programmes:

$$
\begin{aligned}
& \mathrm{C}_{6}-1: 50^{\circ}-200^{\circ} \mathrm{C} / \mathrm{min} . \\
& \mathrm{C}_{6}-2: 100^{\circ} \mathrm{C} \text { isothermal } \\
& \mathrm{C}_{6}-3: 100^{\circ}-200^{\circ} \mathrm{C} \text { at } 2^{\circ} \mathrm{C} / \mathrm{min} .
\end{aligned}
$$

$G C$-analyses: Samples were analysed at the OVRI, the Department of Oenology, the University of Stellenbosch and the BFA für Rebenzüchtung Geilweilerhof. Instruments used were, respectively, Varian 3700 equipped with column $\mathrm{C}_{3}$ and dual FID, TSD detectors, Perkin Elmer 990 equipped with column $\mathrm{C}_{6}, 1: 9$ effluent split and FID detector and Siemens L350 equipped with column $\mathrm{C}_{4}$, and a FID detector. Sample sizes varied between $2,5 \mu \ell$ and 50 $\mu \ell^{\circ}$.

$G C$-effluent sensory evaluation: Various samples were analysed on three different instruments. At Geilweilerhof the samples were analysed on the instrument described by Rapp et al. (1980) equipped with column $C_{2}$. Work at the University of Stellenbosch was performed on a Perkin Elmer 990 equipped with column $\mathrm{C}_{6}$. At the OVRI the TSD detector was removed and samples were sniffed at the detector base. Samples analysed included both headspace and freon 11 extracts of Sauvignon blanc grapes and a standard sample containing $10 \mathrm{ppm}$ each of 2-ethyl3-methoxypyrazine (EMP); 2-isopropyl-3-methoxypyrazine (PMP) and 2-isobutyl-3-methoxypyrazine (BMP) dissolved in freon 11. A second solution from which the PMP had been omitted was also analysed. Retention times of these compounds were compared to those of areas with pyrazine-like aromas noted during analyses of various Sauvignon blanc extracts by rewinding the chart paper, and re-running the aromagram of the standard solution on the same length of chart paper as used for the grape extract.

Preparative GC: Fractionation was performed on a Perkin Elmer 990 instrument equipped with column $\mathrm{C}_{6}-3$. The column effluent was trapped in clean glass tubes cooled with solid $\mathrm{CO}_{2}$; sealed with a small flame immediately after sampling, and stored at $-15^{\circ} \mathrm{C}$. The collected fractions were washed from the tubes with pure $\mathrm{CH}_{2} \mathrm{Cl}_{2}$ and concentrated to $<50 \mu l$ on a water bath at $47^{\circ} \mathrm{C}$.

Gas chromatography - mass spectrometry (GC-MS): All samples prepared during 1981 were analysed on a Finnigan 3200 instrument at Geilweilerhof. All other samples were analysed at Rupert International on a Finnigan 4510 GC-MS-DS instrument, equipped with column $\mathrm{C}_{5}$

Samples analysed consisted of the following:

(a) A standard solution in freon 11 consisting of $10 \mathrm{ppm}$ of each of the following: 2-isobutylthiazole (BT), EMP, PMP, 2-sec-butyl-3-methoxypyrazine (SMP) and BMP.

(b) A basic fraction prepared from a freon 11 extract of Sauvignon blanc grapes harvested at Paarl at between $15^{\circ}$ and $18^{\circ} \mathrm{B}$ during 1982 .

(c) A standard solution of $1,5 \mathrm{ppm}$ trans-2, cis-6-nonadienal in freon 11 .

(d) A sample prepared by preparative GC in which the portion of the extract eluting at the retention time of trans-2, cis-6-nonadienal was collected.

The selected ion monitoring (SIM) technique was applied to samples (a) and (b) described above. Ten ions were observed viz: $\mathrm{m} / \mathrm{e}$ 58; $93 ; 99 ; 107 ; 123 ; 137 ; 138 ; 151$

\begin{tabular}{|c|c|c|c|c|c|}
\hline $\begin{array}{l}\text { Peak } \\
\text { No. }\end{array}$ & Identity & $\begin{array}{l}\text { Certainty } \\
\text { of identi- } \\
\text { fication }\end{array}$ & $\begin{array}{l}\text { Peak } \\
\text { No. }\end{array}$ & Identity & $\begin{array}{l}\text { Certainty } \\
\text { of identi- } \\
\text { fication }\end{array}$ \\
\hline- & 2-Ethyl-3-methoxypyrazine & $* * *$ & 57 & Benzaldehyde & $*$ \\
\hline- & 2-Isopropyl-3-methoxypyrazine & $* * *$ & 63 & trans-2, cis-6-Nonadienal & $* *$ \\
\hline- & 2-Isobutyl-3-methoxypyrazine & $* * *$ & 68 & 2-Phenylacetaldehyde & $* *$ \\
\hline 71 & $\alpha$-Terpineol & $*$ & 70 & Salicyl aldehyde & $*$ \\
\hline 76 & trans Pyranoic linalool oxide & $*$ & 86 & trans- 2 , trans-4-Decadienal & $* *$ \\
\hline 78 & cis Pyranoic linalool oxide & $*$ & 40 & trans-Hex-2-enol & $*$ \\
\hline 85 & Geraniol & $*$ & 41 & cis-Hex-2-enol & $* *$ \\
\hline 97 & 3,7-Dimethyl-1,5-dien-3,7-diol & $*$ & 48 & Heptanol & $*$ \\
\hline 51 & Methional & $*$ & 50 & 2-Ethyl hexanol & $*$ \\
\hline 98 & Benzothiazole & $*$ & 56 & Octanol & $* *$ \\
\hline 36 & Hexanal & $*$ & 88 & Benzyl alcohol & $* *$ \\
\hline 38 & Hept-2-enal & $*$ & 91 & 2-Phenyl ethanol & $*$ \\
\hline 44 & Nonanal & $*$ & 82 & Methyl salicylate ${ }^{1}$ & $*$ \\
\hline 45 & trans-2, cis-4-Hexadienal & $* *$ & 84 & Hexanoic Acid & $*$ \\
\hline 46 & trans- 2 , trans -4 -Hexadienal & $* *$ & 94 & Ditertiarybutyl-p-cresol & $*$ \\
\hline 53 & trans-2, cis-4-Heptadienal & $* *$ & 96 & Phenol & $*$ \\
\hline 55 & trans-2, trans-4-Heptadienal & $* *$ & & & \\
\hline
\end{tabular}

TABLE 1

Aroma components identified in grapes of $V$. vinifera $\mathrm{cv}$. Sauvignon blanc

*Mass spectrum identical to spectra of compounds previously identified at Geilweilerhof.

**Mass spectrum and retention time identical to that of authentic reference compound analysed under identical conditions.

***Identified by comparing selected ion current profiles of a standard solution of pyrazines to the selected ion current profiles of the same ions recorded for a grape extract. Retention times not identical but well within the experimental error (see text).

${ }^{1}$ Probably an artifact of sample preparation technique. 


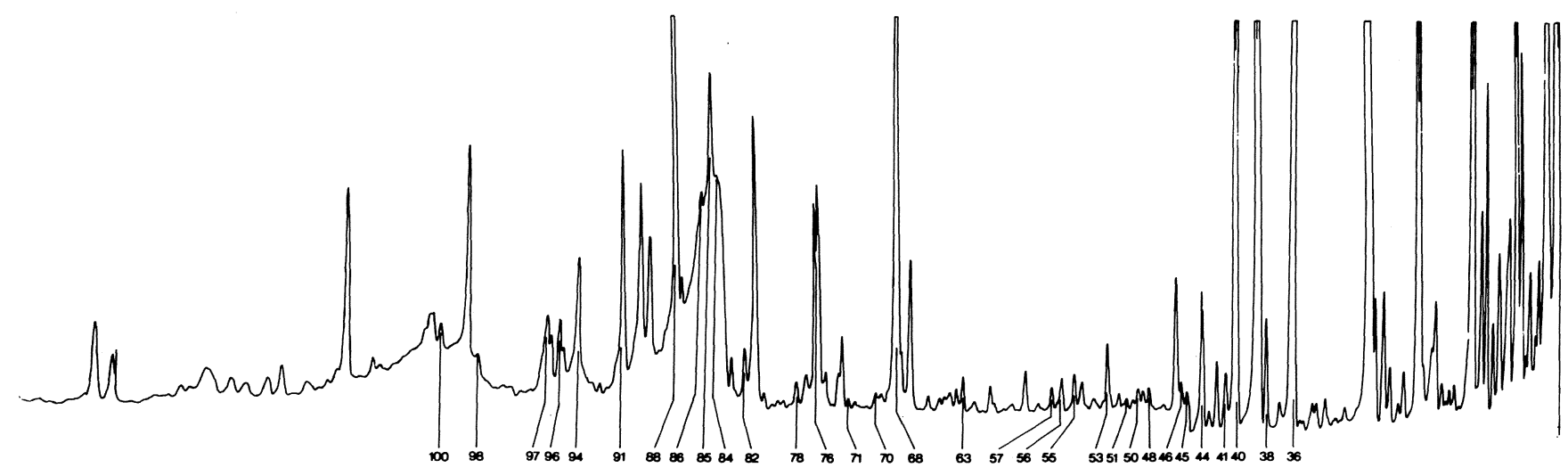

Fig. 1

Reconstructed total ion current obtained during mass spectral analysis of a freon 11 extract of $V$. vinifera cv. Sauvignon blanc grapes. Peak numbers correspond to numbers in Table 1 .

and 152. The standard solution (sample a) was also analysed in the normal mode, as were samples (c) and (d).

Problems were experienced with precise repetition of retention times upon repeated injection of the same sample. Shifts of up to 60 seconds in retention time were found to be within the experimental error. All peaks in a single run did not necessarily shift to the same degree, and peaks were observed to move closer together or further apart, while other peaks appeared close to the expected retention time.

\section{RESULTS AND DISCUSSION}

The volatile aroma components identified during this study are listed in Table 1 . A reconstruction of the total ion current profile, obtained during mass spectral analysis of a freon 11 extract of Sauvignon blanc grape juice on the Finnigan 3200 instrument, is depicted in Fig. 1. Most of these components have been identified in other grape cultivars, whereas the presence of others have not been reported before. Consequently, in this report emphasis will be placed on the latter components.

Sensory analyses of Sauvignon blanc extract by GC effluent sniffing: The pyrazine-like aroma observed while tasting fresh Sauvignon blanc grape berries was recognised in two distinct fractions of the gas chromatograph effluent. These characteristic fractions were recognised on three different instruments respectively equipped with columns $C_{2}, C_{3}$ and $\mathrm{C}_{6}-1$. The first of these fractions (Fig. 2, area 1) exhibited a complex aroma combining a potato-like aroma with the typical green pepper-like aroma characteristic of many 3-alkyl-2-methoxypyrazines (Parliment \& Epstein, 1973). The second fraction (Fig. 2, area 3) had a more intense pure green pepper aroma. The aroma intensities of fractions 1 and 3 were significantly higher in the freon 11 extracts than in the extract of the headspace concentrate, the first fraction (Fig. 2, area 1) being barely detectable in the headspace sample.

Comparison of four naturally occurring methoxypyrazines with the retention times of the pyrazine-like fractions in the aromagrams (Fig. 2, area 1 and 3), indicated that three of these compounds could possibly be present in the extracts examined. EMP and PMP could not be separated under the GC conditions used in this study (columns $\mathrm{C}_{4}+$ $\mathrm{C}_{6}$ ), although by utilizing extremely dilute samples, it was demonstrated that EMP emerged fractionally before PMP.
The retention times of these compounds fell within area 1 (Fig. 2), while the retention time of BMP fell within area 3 (Fig. 2). Subsequent sensory analyses of a standard solution of EMP and BMP in freon 11 and a concentrated freon 11 grape extract, under isothermal conditions (column $\mathrm{C}_{6}-2$ ), confirmed that the retention times of the pyrazine aromas detected in both samples coincided exactly.

Examination of the chromatograms of the same freon 11 grape extract on an instrument equipped with an effluent splitter and both a FID and TSD detector (column $\mathrm{C}_{3}$ ) failed to indicate the presence of any pyrazines in the sample (Fig. 2B). After spiking the sample with approximately 40 ng of each of EMP, PMP and BMP the pyrazines were, however, clearly visible in the chromatogram (Fig. 2C).

Gas chromatography - mass spectrometry (GC-MS): GCMS analyses of a headspace sample as well as a freon 11 extract of Sauvignon blanc grapes failed to indicate the presence of a single pyrazine (Finnigan 3200). From these results it was clear that either the pyrazines were not present in the samples or their concentrations were lower than the detection limits of the instrument as used in this study.

In order to obtain maximum concentration of any pyrazines present in these grapes a basic fraction was separated from the freon 11 extract of $18 \mathrm{~kg}$ of Sauvignon blanc grapes. Pistre \& Boubals (1978) as well as Cordonnier \& Bayonove (1978) noted that the pyrazine-like flavour of Cabernet Sauvignon decreased with increasing grape maturity. For this reason the Sauvignon blanc grapes from Paarl were harvested at between $15^{\circ}$ and $18^{\circ}$ Balling. The concentrated basic fraction was analysed on the Finnigan 4510 instrument using the SIM technique in an effort to further enhance the possibility of detecting even lower concentrations (Garland \& Powell, 1981).

Complete spectra as well as selected ion current profiles (SICPs), monitoring ions $\mathrm{m} / \mathrm{e} 58 ; 93 ; 107 ; 123 ; 124 ; 137$; $138 ; 151$ and 152 , were recorded for a standard solution containing $100 \mathrm{ppm}$ of each of the following: BT, EMP, PMP, SMP and BMP. The BT was included in the sample because it has a green, tomato-like aroma and a retention time just short of the first pyrazine-like aroma fraction detected in the aromagram depicted in Fig. 2. SMP was included in the sample because it is found in a large variety of vegetables in association with PMP and BMP (Murray \& Whitfield, 1975). 


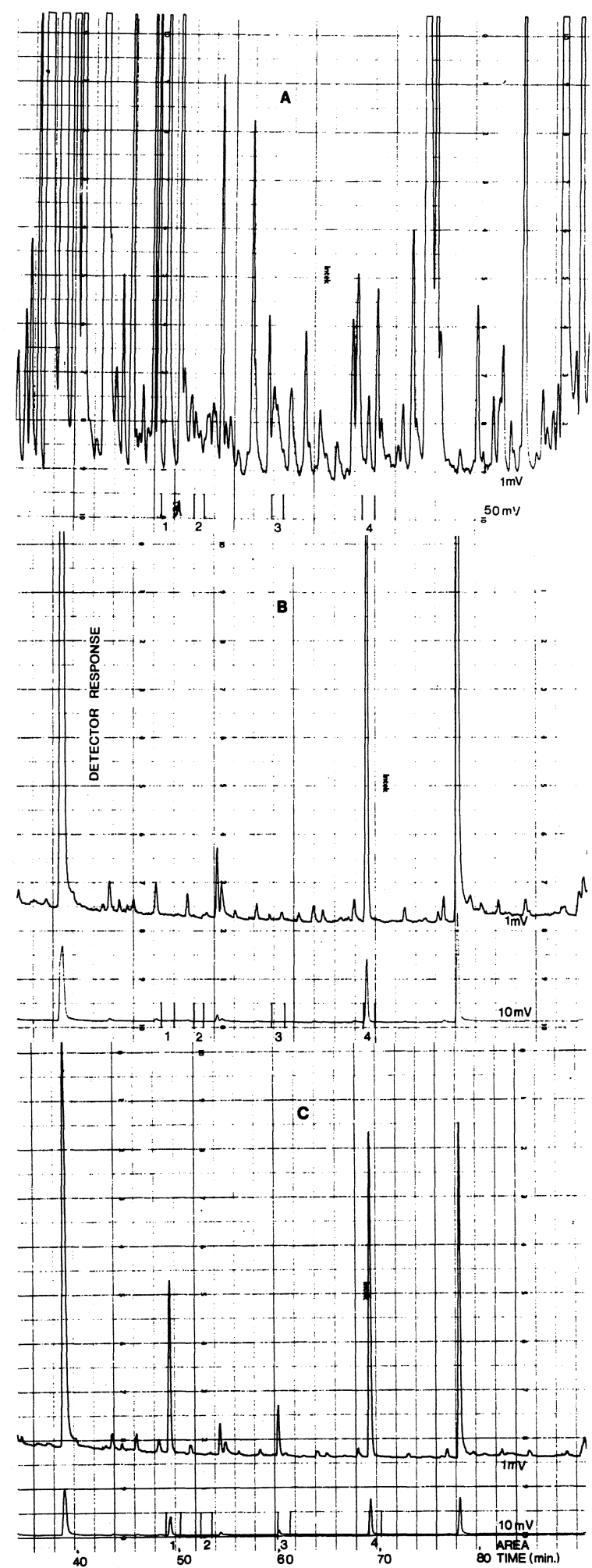

Fig. 2

Sections of chromatograms of a freon 11 extract of $V$. vinifera cv. Sauvignon blanc grapes. (A) Section of FID chromatogram of freon 11 extract of $V$. vinifera cv. Sauvignon blanc grapes., (B) Same as A but equivalent nitrogen specific detector trace., (C) As B but with addition of three pyrazines to concentrate.

Area 1: Typical earthy/potato-like aroma closely followed by a strong green pepper aroma.

Area 2: Strong potato-like aroma.

Area 3: Strong green pepper aroma.

Area 4: Strong green, cucumber-like aroma.
Comparison of the SICPs of the standard solution and the basic extract clearly indicated that no measurable amounts of BT and SMP were present in the extract examined in this study. The complete SICPs are not illustrated here but relevant portions of these profiles are depicted in Fig. 3A and B (standard solution) and Fig. 4A and $B$ (basic fraction of grape extract). The full mass spectra for EMP, PMP and BMP are illustrated in Fig. 5.

The problems encountered in precisely reproducing retention times on repeated injection of a single sample were mentioned in the previous section. This factor should be taken into account when perusing Fig. 3 and Fig. 4. As the quantities of pyrazines detected here were minute, the SICPs of many ions were weak. It was, therefore, decided not to normalize all profiles to $100 \%$ but to present them in such a way that even the weakest significant ion is clearly visible.

From Fig. 5C it is clear that the m/e 124 ion dominates the spectrum of BMP. The next most intense ions are $\mathrm{m} / \mathrm{e}$ 94 and 151. The $\mathrm{m} / \mathrm{e} 93$ ion was recorded during this work as this ion is visible in the spectra of all the pyrazines in the standard solution, whilst the intensity of the m/e 94 ion is very low in the spectrum of EMP.

Considering the ions monitored, the presence of BMP would be indicated by coincidence of $\mathrm{m} / \mathrm{e} 124,151$ and 93, during the same scan at the correct retention time, taking into account the previously mentioned experimental error. Perusing Fig. 4B and comparing the SICPs illustrated with the SICPs in Fig. 3B clearly indicates the presence of BMP in the basic fraction analysed here. The ratios of ions m/e 124 and 151 are as expected (Fig. 5), while that of $\mathrm{m} / \mathrm{e} 93$ is slightly higher than expected, possibly due to the interference of an unknown compound (Fig. 4B). This evidence, together with the coincidence between the aroma of a geniune pyrazine sample and that of the pyrazine-like aroma in the grape extract (Fig. 2) at the same retention times, leaves little doubt as to the validity of identification.

Although EMP and PMP could not be separated on column $\mathrm{C}_{4}$ they were partially separated on column $\mathrm{C}_{5}$ used in the Finnigan 4510 instrument. The presence of EMP in the basic extract would be indicated by the coincidence of respectively m/e 138, 137, 124, 123, 107 and 93, whilst the presence of PMP would require the coincidence of $\mathrm{m} / \mathrm{e} 137,152,124$ and 93 (Fig. 5).

Comparison of the SICPs in Fig. 4A with those in Fig. $3 \mathrm{~A}$ indicates that the compound detected by scan number 583 (Fig. 4A) and EMP at scan number 568 (Fig. 3A) appear to be identical. The discrepancy of 22,5 seconds in the retention time (scan time $=1,5 \mathrm{~s}$ ) is well within the experimental error (see Materials and Methods). Ions $\mathrm{m} / \mathrm{e}$ $138,123,137$ and 124 appear at the same scan number (583, Fig. 4A) in the ratios expected for EMP (Fig. 5A). Ion $\mathrm{m} / \mathrm{e} 107$ is, however, obscured by the appearance of an intense ion interfering at scan number 584 (Fig. 4A), whilst the m/e 93 ion is not visible in Fig. 4A because of the appearance of an intense $\mathrm{m} / \mathrm{e} 93$ ion at scan number 616 (not illustrated in Fig. 4A). By selecting different scan limits the $\mathrm{m} / \mathrm{e} 93$ ion at scan number 583 appears in the ratio expected for EMP (Fig. 5A). As in the case of BMP, combining these results with those from the GC-effluent analyses (Fig. 2) leaves little doubt as to the presence of EMP in the extracts examined. EMP was tentatively identified as a constituent of potato aroma by Buttery \& Ling 


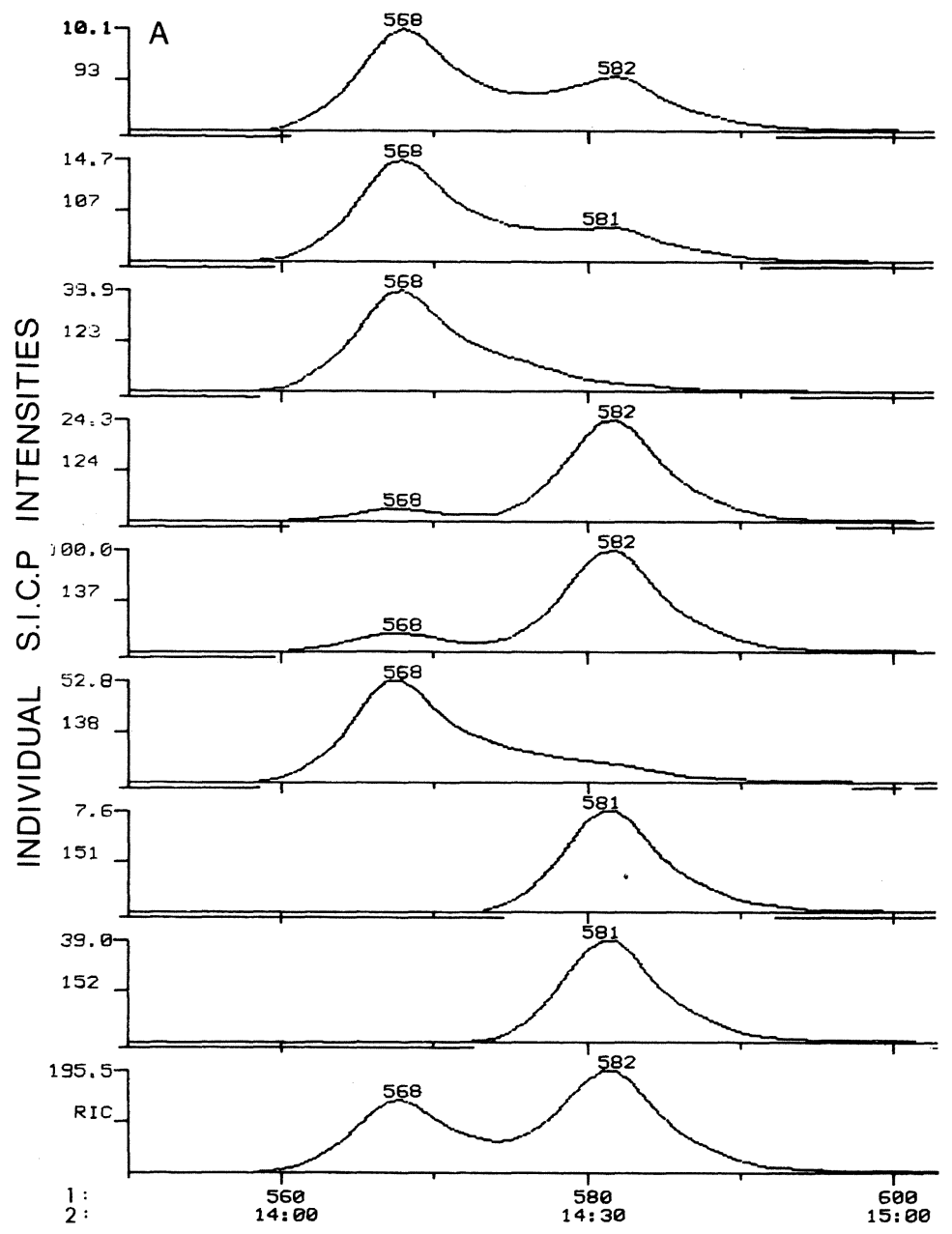

1: SCAN NO.

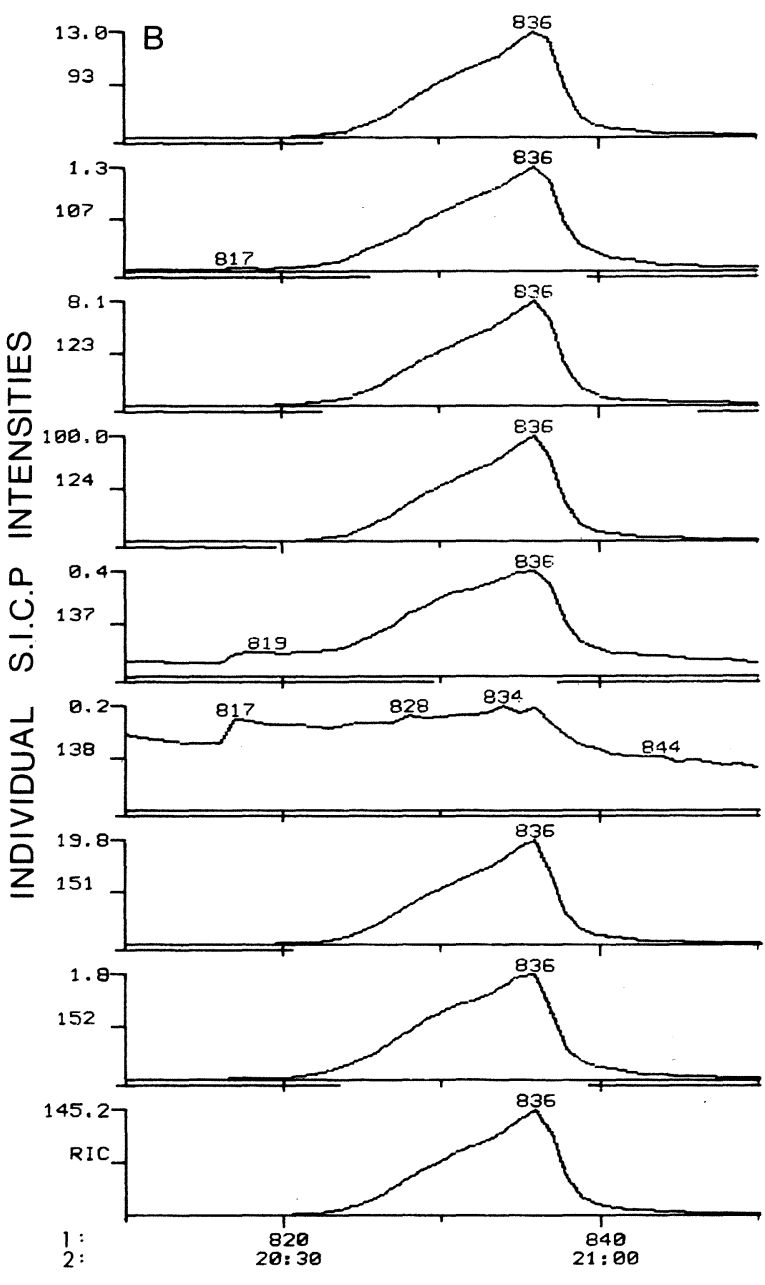

2: TIME (MIN.)

Fig. 3

Relevant region of the non-normalised SICPs recorded for a pyrazine standard solution. (A) 2-ethyl-3-methoxypyrazine (scan no. 568) and 2-isopropyl3-methoxypyrazine (scan no. 582), (B) 2-isobutyl-3-methoxypyrazine (scan no. 836).

(1973) and Nursten \& Sheen (1974). Subsequent analyses of potatoes by Murray \& Whitfield (1975) failed to reveal any trace of this compound in potatoes. These authors, therefore, concluded that the available evidence for the acceptance of EMP as a naturally occurring aroma component was insufficient.

The evidence for the presence of PMP is less clear. The compound with base peak at $\mathrm{m} / \mathrm{e} 137$ (scan number 592) could well be PMP as the second most intense peak in the PMP spectrum (m/e 152$)$ is also present at this retention time. The ratio of these peaks is not, however, as expected from Fig. 5 with the m/e 152 peak measuring only $26 \%$ of the base peak instead of an expected $41 \%$. The ion $\mathrm{m} / \mathrm{e}$ 124 , the third most intense peak in the PMP spectrum, is recorded at scan number 593. According to Ten Noever de Brauw (1981) this ion should be considered as an interfering peak that does not belong to the spectrum of the compound detected at scan number 592. During this study it was, however, noticed that flat-topped SICP peaks were sometimes allotted a scan number greater or lesser by one unit than the expected scan number. This is well illustrated in Fig. 3A where both m/e 151 and 152 are recorded at scan number 581 , while the remainder of the ions are recorded at scan number 582. It is, therefore, not unreasonable to assume that $\mathrm{m} / \mathrm{e} 124$ is indeed part of the spectrum of the compound detected at scan number 592.

The aroma of EMP has been described as raw potato (Seifert et al., 1970) and earthy bell pepper (Parliment \& Epstein, 1973), and that of PMP as earthy bell pepper (Parliment \& Epstein, 1973), bell pepper and raw potato (Seifert et al., 1970) and green peas (Murray \& Whitfield, 1975). During GC-effluent sensory evaluation the aroma of the first pyrazine-like fraction (Fig. 2, area 1) gave the distinct impression of an earthy, potato-like aroma followed closely by an intense bell pepper aroma, and not of a single aroma that could be described as earthy bell pepper. The presence of two components is thus indicated. PMP occurs in a variety of vegetables in association with SMP and BMP (Murray \& Whitfield, 1975) and its occurrence in Vitis would not be unexpected. It is, therefore, tentatively suggested that PMP is present in grapes of Sauvignon blanc along with EMP and BMP.

Aroma components identified in a freon 11 grape extract: This study centered on the identification of the impact aroma components responsible for the typical grassy, green, pyrazine-like aroma of Sauvignon blanc grapes. During this work thirty additional aroma components were identified, some of which will be discussed below. 


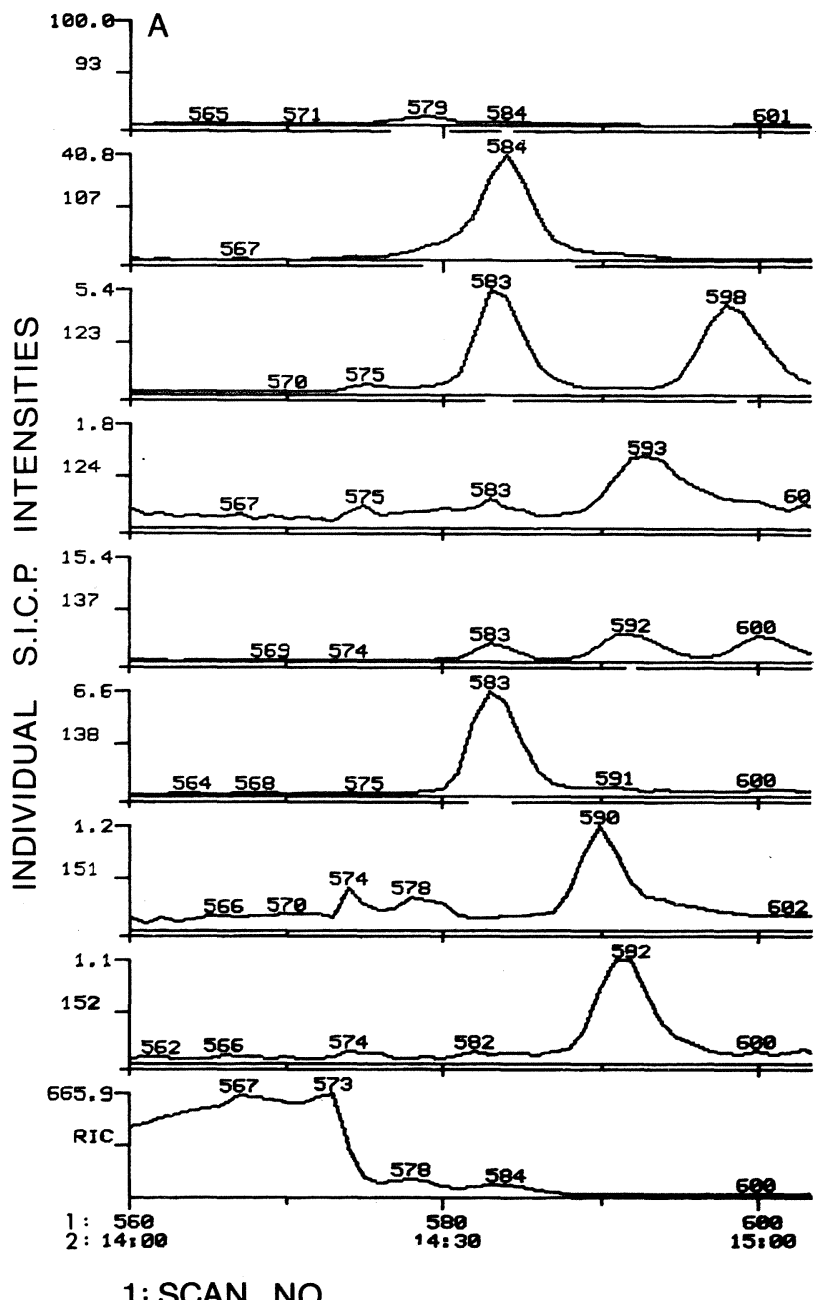

1: SCAN NO.

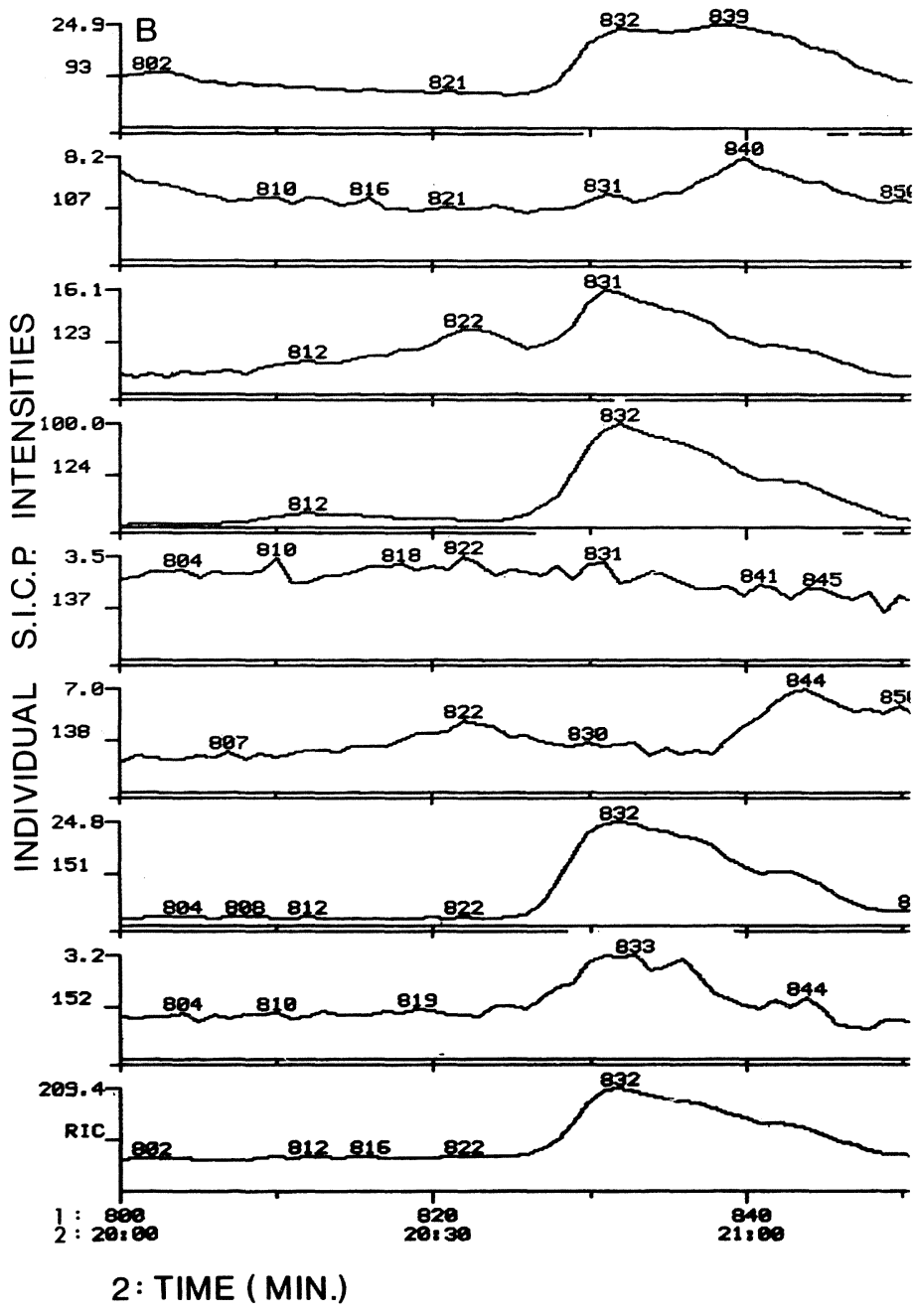

Fig. 4

Relevant regions of the non-normalized SICPs recorded for a basic fraction of a freon 11 extract of $V$. vinifera cv. Sauvignon blanc grapes.

(A) 2-ethyl-3-methoxypyrazine (scan no. 583) and 2-isopropyl-3-methoxypyrazine (scan no. 592), (B) 2-isobutyl-3-methoxypyrazine (scan no. 832).

Five terpenes were identified in the freon 11 extract of Sauvignon blanc grapes (Table 1, Fig. 1). Bayonove \& Cordonnier (1971) had previously identified a small amount of linalool in this cultivar, while Ribereau-Gayon (1973) pointed out that an additional, as yet unidentified terpene, was also present. Chaudhary et al. (1964), however, failed to identify any terpenes amongst the many components that they identified in grapes of this cultivar. The monoterpenes play an important role in the characteristic aroma of the muscat and other aroma related grape cultivars as well as of wines made from these cultivars (Ribereau-Gayon, Boidron \& Terrier, 1975; Schreier, 1979; Williams, Strauss \& Wilson, 1980). Studies by Ribereau-Gayon et al. (1975) indicated the aroma of terpenes to be additive. They found that a mixture of certain terpenes had a threshold value lower than that of the most potent terpene in the mixture. It has further been established that the terpene polyols readily break down to a series of terpene derivatives possessing more potent aromas than the original polyol (Williams et al., 1980). In view of these phenomena it is not entirely inconceivable that the terpenes identified in this study may contribute to the aroma of wines made from Sauvignon blanc, although they are present in relatively small quantities (Fig. 1). It is possible that these components could also contribute to the fruity/floral note that sometimes supplements the typical grassy/pyrazine-like aroma of Sauvignon blanc wines.

Methional (3-methylthio-propanal), previously identified in, amongst others, asparagus, potato, tomato and beans (Van Straten, De Beauveser \& Visscher, 1981), was identified in Vitis for the first time. Methional, a derivative of methionine, is an interesting compound because of its relationship to ethylene production in fruits and vegetables (Ku, Yang \& Pratt, 1967; Shankaranarayana et al., 1974). This compound possesses a characteristic aroma likened to that of potato (Nursten \& Sheen, 1974), and is also responsible for the potato-like aroma recognised in area 2 of the chromatogram illustrated in Fig. 2.

Benzothiazole was first identified in grapes by Schreier, Drawert \& Junker (1976). This compound has a characteristic rubbery aroma and has been implicated as a contributor to stale milk flavour (Ferretti \& Flanagan, 1972).

The alkadienal profile of Sauvignon blanc grapes as shown in Fig. 1 differs greatly from that reported for $V$. vinifera cv. Chenin blanc (Augustyn \& Rapp, 1982). Whereas the trans-2, cis-4- and trans-2, trans-4-decadienal isomers were amongst the major volatile aroma components detected in the latter cultivar, only a small quantity of trans-2, trans-4-decadienal was detected in this 

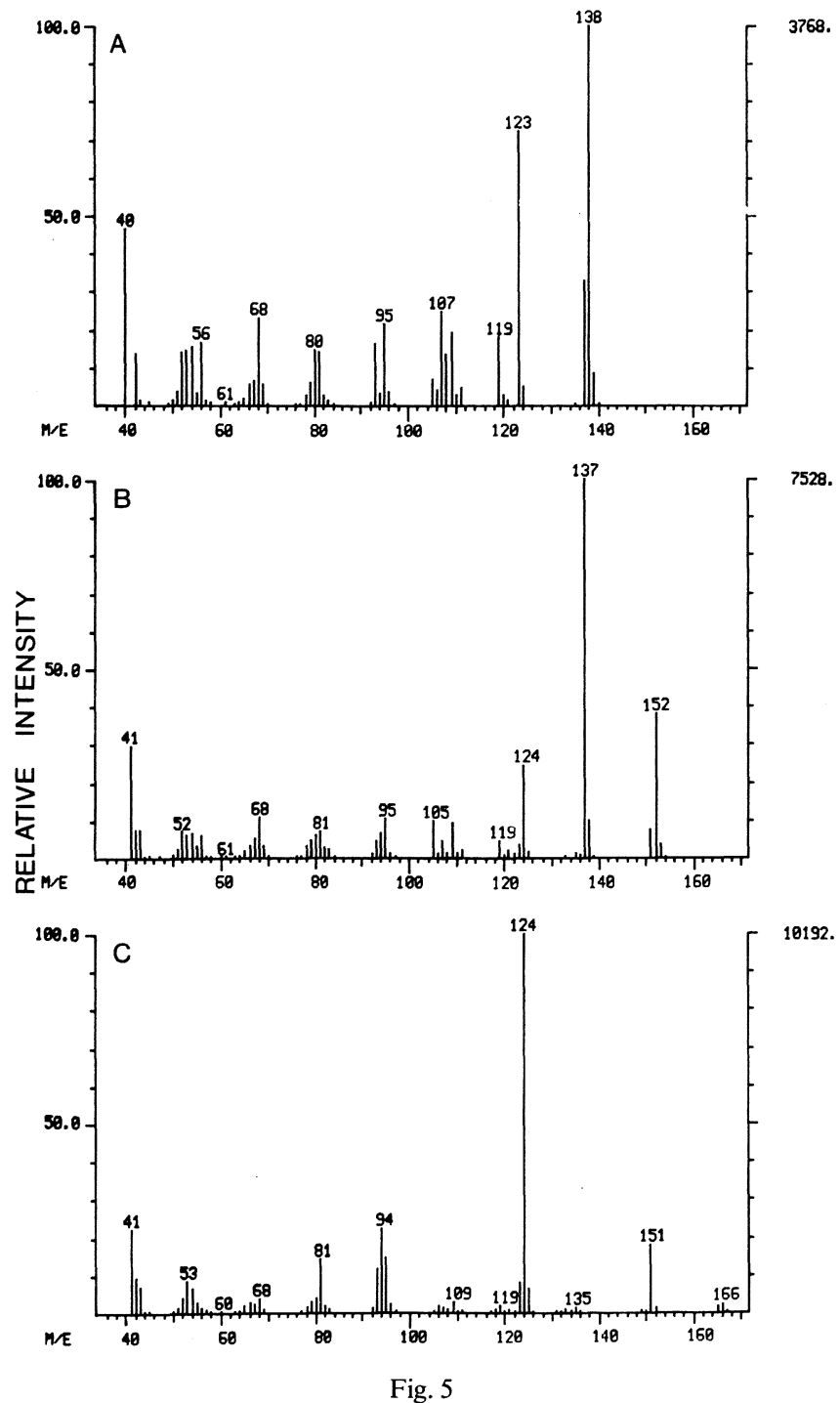

Mass spectra of authentic reference compounds. (A) 2-ethyl-3-methoxypyrazine., (B) 2-isopropyl-3-methoxypyrazine., (C) 2-isobutyl-3-methoxypyrazine.

study. An interesting alkadienal, identified in Vitis for the first time during this work, is trans-2, cis-6-nonadienal, the so-called cucumber aldehyde (Table 1, Fig. 1). This compound was responsible for the green cucumber-like aroma detected in area 4 of the chromatogram illustrated in Fig. 2. This compound, the major volatile responsible for cucumber aroma (Hatanaka, Kujiwara \& Harada, 1975), has also been identified in cowberry, melon, bell pepper, beer and tea (Van Straten et al., 1981).

\section{CONCLUSION}

The identification of 2-ethyl-3-methoxypyrazine, 2-isobutyl-3-methoxypyrazine and possibly 2-isopropyl-3methoxypyrazine in Sauvignon blanc grapes strongly indicates that this series of compounds may indeed contribute to the typical grassy, pyrazinelike aroma associated with grapes and wine of this cultivar. The main portion of the aldehydes identified in grape juice extracts are most likely present in the resultant wine as bisulphite addition products because of the effect of added $\mathrm{SO}_{2}$. In addition some of the aldehydes are reduced to the corresponding alcohols during the course of fermentation. It is, however, not inconceivable that methional and the related methionol, with their characteristic vegetable aromas, could also contribute to the typical Sauvignon blanc aroma. The real significance of these compounds as well as several others eg. the methoxypyrazines and the terpenes, in the aroma of grapes and wines of this cultivar, however, requires further study.

\section{LITERATURE CITED}

AMERINE, M. A., 1982. The changing preferences for wines. Food. Technol. 36(1), $106-110$.

AUGUSTYN, O. P. H. \& RAPP, A., 1982. Aroma components of Vitis vinifera $\mathrm{L}$. cv. Chenin blanc grapes and their changes during maturation. S. Afr. J. Enol. Vitic. 3 (2), $47-51$.

BAYONOVE, C. \& CORDONNIER, R., 1971. Le Linalol, constituent important mais non specifique de l'arôme des muscats. C.R. Ac. Agric. Fr. 57, 1374 1378.

BAYONOVE, C., CORDONNIER, R. \& DUBOIS, P., 1975. Etude d'une fraction caracteristique de l'arôme du raisin de la variété Cabernet Sauvignon; mise en evidence de la 2-methoxy-3-isobutylpyrazine. C. $R$. Acad. Sci. Ser. D. 281, 75- 78.

BUTTERY, R. G. \& LING, L. C., 1973. Earthy aroma of potatoes. J. Agric. Food Chem. 21, 745 - 746.

BUTTERY, R. G., SEIFERT, R. M., GUADAGNI, D. G. \& LING, L. C., 1969. Characterization of some volatile constituents of bell peppers. J. Agric. Food Chem. 17, 1322 - 1327.

CHAUDHARY, S. S., KEPNER, R. E. \& WEBB, A. D., 1964. Identification of some volatile compounds in an extract of the grape, Vitis vinifera var. Sauvignon blanc. Am. J. Enol. Vitic. 15, 190 - 198.

CORDONNIER, R. \& BAYONOVE, C., 1978. Les composantes variétales et préfermentaires de l'arôme des vins. Parfums, Cosmetiques, Arômes 24, 64 - 77.

FERRETTI, A. \& FLANAGAN, V. P., 1972. Steam volatile constituents of stale non-fat dry milk. The role of the Maillard reaction in staling. J. Agric. Food Chem. 20, 695-698.

GARLAND, W. A. \& POWELL, M. L., 1981. Quantitative selected ion monitoring (QSIM) of drugs and/or drug metabolites in biological matrices. J. Chrom. Sci. 19, $392-434$.

HATANAKA, A., KUJIWARA, T. \& HARADA, T., 1975. Biosynthetic pathway of cucumber alchohol: trans-2, cis-6-nonadienol via cis-3, cis-6-nonadienal. Phytochem. 14, 2589 - 2592.

KU, H. S., YANG, S. F. \& PRATT, H. K., 1967. Enzymic evolution of ethylene from methional by a pea seedling extract. Arch. Biochem. Biophys. 118, $756-758$.

MURRAY, K. E. \& WHITFIELD, F. B., 1975. The occurence of 3-alkyl-2-methoxypyrazines in raw vegetables. J. Sci. Food Agric. 26, 973 - 986.

NURSTEN, H. E. \& SHEEN, M. R., 1974. Volatile flavour components of cooked potato. J. Sci. Food Agric. 25, 643 - 663 .

PARLIMENT, T. H. \& EPSTEIN, M., 1973. Organoleptic properties of some alkyl substituted alkoxy and 
alkylthiopyrazines. J. Agric. Food Chem. 21, 714 716.

PISTRE, R. \& BOUBALS, D., 1978. Transmission héréditaire du goût de "Cabernet-Sauvignon" dans les croisements de cette varité avec des cépages du Sud de la France. Genetique et Amelioration de la France. Genetique et Amelioration de la Vigne. Il Symposium internationale su l'amelioration de la vigne. Paris: INRA, 435 - 443.

RAPP, A. \& KNIPSER, W., 1980. Eine neue Methode zur Anreicherung von Dampfkomponenten. Dargestellt am Beispiel des Weines. Chromatographia 13, $698-702$.

RAPP, A., KNIPSER, W., ENGEL, L., ULLEMEYER, H \& HEIMANN, W., 1980. Fremdkomponenten im Aroma von Trauben und Weinen interspezifischer Rebsorten I. Die Erdbeernote. Vitis 19, 13- 23.

RIBEREAU-GAYON, J., 1973. Recherche des relations entre les caracteres sensoriels des vins rouges et leur composition. Conn. Vigne Vin. 7, 79-92.

RIBEREAU-GAYON, P., BOIDRON, J. N. \& TERRIER, A., 1975. Aroma of muscat grape varieties. $J$. Agric. Food Chem. 23, 1042 - 1047.

SCHREIER, P., 1979. Flavor composition of wines: A review. CRC. Crit. Rev. Food Sci. Nutr."12, 59-111.

SCHREIER, P., DRAWERT, F. \& JUNKER, A., 1976. Identification of volatile constituents from grapes. $J$. Agri. Food Chem. 24, 331 - 336.
SEIFERT, R. M., BUTTERY R. G., GUADAGNI, D. G., BLACK, D. R. \& HARRIS, J. G., 1970. Synthesis of some 2-methoxy-3 alkylpyrazines with strong bell pepper-like odours. J. Agric. Food Chem. 18, 246 - 249.

SHANKARANARAYANA, M. L., RAGHAVAN, B., ABRAHAM, K. O. \& NATARAYAN, C. P., 1974. Volatile sulfur compounds in food flavours. CRC. Crit. Rev. Food Technol. 4, 395 - 435.

TEN NOEVER DE BRAUW, M. C., 1981. The horizons of identification and analysis with mass spectrometry. Flavour 81. 3rd Weurman Symposium, Proceedings of the International Conference, Munich 1981. Berlin: Walter de Gruyter. 253 - 285.

VAN STRATEN, S., DE BEAUVESER, J. C. \& VISSCHER, C. A., 1981. Volatile compounds in food, supplement 6, Zeist - the Netherlands: Central Institute for Nutrition and Food Research.

WILLIAMS, P. J., STRAUSS, C.R. \& WILSON, B., 1980. Hydroxylated linalool derivatives as precursors of volatile monoterpenes of muscat grapes. J. Agric. Food Chem. 28, 766 - 771.

WINKLER, A. J., COOK, J. A., KLIEWER, W. M. \& LIDER, L. A., 1974. General Viticulture. Univ. Calif. Press., Berkeley. 